\title{
Habitat associations and occupancy patterns of burnet moths (Zygaenidae) in semi-natural pastures in Sweden
}

\author{
Markus Franzén \& Thomas Ranius
}

Franzén, M. \& Ranius, T. 2004: Habitat associations and occupancy patterns of burnet moths (Zygaenidae) in semi-natural pastures in Sweden. - Entomol. Fennica 15: 91-101.

Burnets were surveyed in 100 semi-natural pastures in the province of Östergötland, southeastern Sweden. We analysed the presence/absence of burnets in relation to habitat characteristics, and species richness of butterflies and plants. Five species were found (Adscita statices, Zygaena osterodensis, Z. viciae, Z. filipendulae and Z. lonicerae), all occurring in 33\%-36\% of the localities. Among these, four are nationally red-listed. More species were found on (1) large semi-natural pastures, compared with small, (2) low- to medium-grazed semi-natural pastures, compared with heavily grazed, and (3) open semi-natural pastures, compared with wooded. A. statices and Z. viciae had a higher frequency of occupancy at localities surrounded by a large density of pastures, but the occurence of the other species did not rely on this variable. The number of burnet species per locality was positively correlated with the number of butterfly species, and slightly positively correlated with species richness of plants. The difference in species richness among burnets, butterflies and plants may be explained by different responses to grazing pressure; the species richness of burnets and butterflies peaked in localities with a low grazing pressure, while species richness of plants was unaffected by grazing. As burnets are easily surveyed and indicate a high butterfly-species richness, they may be suitable indicators of species richness of pastures. As uniform management with heavy grazing is detrimental for burnets and for many butterflies, it should be avoided at localities with a speciesrich fauna.

M. Franzén, University of Lund, Department of Animal Ecology, Ecology Building, SE-22362 Lund, Sweden; E-mail Markus.Franzen@zooekol.lu.se

T. Ranius, Swedish University of Agricultural Sciences, Department of Entomology, P.O. Box 7044, SE- 75007 Uppsala, Sweden.

Received 3 October 2003, accepted 19 November 2003

\section{Introduction}

Burnets (Zygaenidae) are day-active Lepidoptera with a biology similar to many butterflies (Tremewan 1985). Many burnets seem to have a limited mobility (Bourn 1995, Naumann et al.
1999, Menéndez et al. 2002) and are often restricted to small areas (Ravenscroft \& Young 1996, Crispin \& Warrington 1997). At suitable habitats, they may be abundant (Bourn 1995, Naumann et al. 1999). The population structure of some burnets shows similarities with butter- 
flies known to occur in metapopulations (Ravenscroft \& Young 1996, Gutiérrez et al. 2001). Adult burnets are frequent visitors of flowers where they feed on nectar (Tremewan 1985, Crispin \& Warrington 1997), and locally burnets have been found to be the dominating pollinators of rare orchids (Lind \& Lindeborg 1989, Nazarov 1993).

Many butterfly species have been studied in detail regarding their habitat requirements (e.g. Thomas 1984, Thomas 1994, Hanski \& Thomas 1994, Pullin 1995, Cowley et al. 2001, Asher et al. 2001). Knowledge of burnets is scanty, compared to that of many butterflies; the distribution of many European burnets is not fully known (Naumann et al. 1999, Huldén et al. 2000, Asher et al. 2001, Saarinen et al. 2003) and no international red lists for burnets have been compiled, as there exist for butterflies (van Swaay \& Warren 2003). In Europe, a great decline in the distribution of burnets has been documented during the last century (Mikkola 1979, Zarzycki \& Dabrowski 1986, Mikkola 1987, Barbour \& Waring 1991, Väisänen \& Somerma 1993, Kulfan \& Kulfan 1996, Gärdenfors 2000). In Finland and Sweden, there are old records from some provinces where they now are absent (Väisänen \& Somerma 1993, Gärdenfors 2000). In Norway, Z. lonicerae has disappeared from vast areas (Hansen \& Aarvik 2000). Z. viciae went extinct from the largest locality in Great Britain, New Forest, in 1927 and is currently known only from one site in Britain (Ravenscroft et al. 1993).

Burnets occur mainly on dry grasslands, and one of their most important habitat types is seminatural pasture (Naumann et al. 1999). Over the past 100 years, the area of semi-natural grasslands has substantially decreased in Europe (e.g. van Swaay \& Warren 2003). Since the late 1950 's, the area of semi-natural pastures (used for grazing) in Sweden has decreased by $30 \%$ (Anon. 1990). Meadows (used for hay-making) have decreased even more, and today only $0.5 \%$ remains of the area present in the late 1950's (Anon. 1990). Consequently, many species living on semi-natural grassland are red-listed (e.g. Gärdenfors 2000). In Sweden, and many other countries in Western Europe, conservation of seminatural pastures has mainly been based on management that aims at maintaining grazing-dependent and sun-demanding flora (Ekstam \&
Forshed 1992, Watkinson \& Ormerod 2001). Other organisms in semi-natural pastures do not necessarily have the same habitat requirements as these plants, and that may explain why the species richnesses of different taxa in pastures do not often correlate (Pärt \& Söderström 1999, Vessby et al. 2002, Kruess \& Tscharntke 2002).

Conservation of semi-natural pastures should preferably be based not only on the flora, but also knowledge about requirements of insects, as they are the most species-rich taxon. However, there is usually lack of time, economic resources or taxonomic expertise to carry out inventories for each insect taxa (Oliver \& Beattie 1996) and for that reason it may be useful to identify biodiversity indicators, viz. groups of species that are associated with a high total biodiversity (McGeoch 1998). Naumann et al. (1999) suggest burnets as an indicator group, but their potential as predictors of species richness of other taxa has never been tested.

The aim of this study was to analyse the occupancy patterns of burnets in relation to habitat characteristics. We collected presence/absence data of burnet moths in semi-natural pastures in southeastern Sweden, and tried to relate their species richness to the species richness of butterflies and plants, both taxa that are often used as indicators. We explored whether the difference in species richness between these three organism groups may be explained by different response to locality characteristics. Based on this information, the potential for using burnet moths as biodiversity indicators was discussed.

\section{Methods and study area}

\subsection{Study area, and locality variables}

The study was carried out in 100 semi-natural pastures in the province of Östergötland, southeastern Sweden. One of the highest concentrations of semi-natural pastures on the Swedish mainland occurs in southwestern Östergötland (Lindahl 1997; Fig. 1), while the density is much lower in the southern and northwestern parts that are dominated by forest land (Anon. 1996).

The survey was conducted on ancient pastures of which the majority were grazed by cattle. 
Fig. 1. - a. The density of semi-natural pastures according to the ancient meadows and pastures survey in the province of Östergötland, Sweden (Måreby 1991). - b. Coverage $(\%)$ of pastures within $5 \times 5 \mathrm{~km}$ squares.
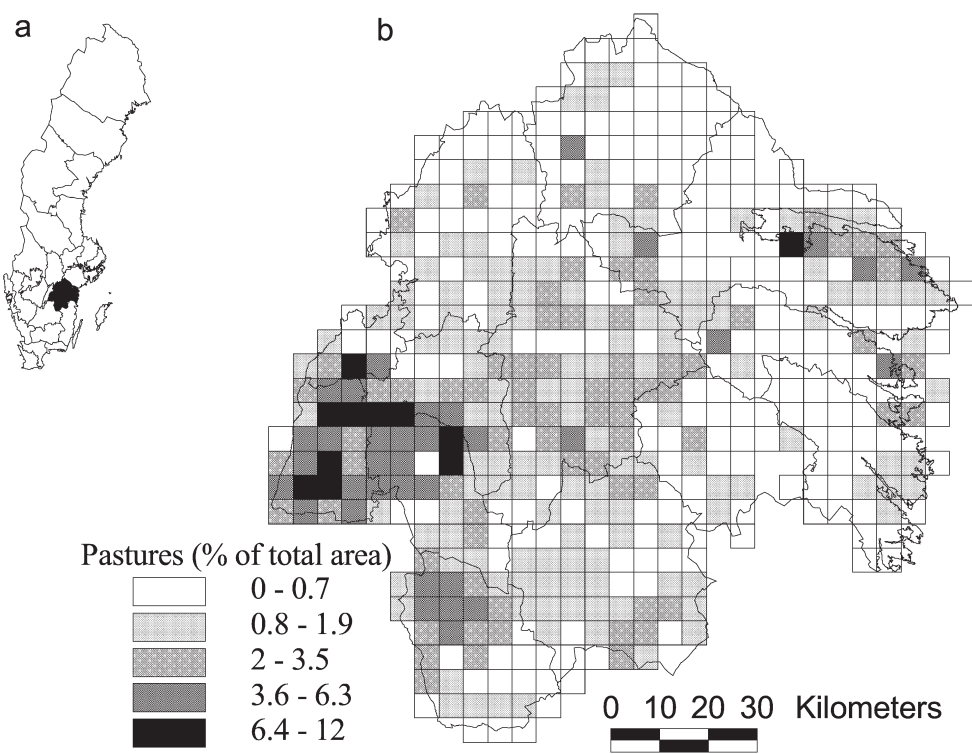

Recently abandoned localities that have retained biological characteristics of ancient grassland were exceptionally included in the survey. Mainly localities known to have a rich flora of vascular plants were selected for sampling. The distance between surveyed localities was at least $1 \mathrm{~km}$. Localities apparently affected by active fertilization or cultivation activities were not included in the survey.

The localities were described by variables possibly reflecting habitat quality (Table 1 ). For some of these variables, the data were from the Ancient Meadows and Pastures Survey (Måreby 1991), while others were estimated at the inven- tory. Plant data were only available for 92 of the 100 surveyed localities. An index of the density of semi-natural pastures in the surrounding was calculated as follows:

$\operatorname{Index}=\left(N_{1} / \check{N}_{1}\right)+\left(N_{10} / \check{N}_{10}\right)+\left(A_{1} / \breve{A_{1}}\right)+\left(A_{10} / \breve{A}_{10}\right)$

where $N_{1}$ is the number of semi-natural pastures within $1 \mathrm{~km}$ from the surveyed locality, $N_{10}$ is the number of semi-natural pastures within $10 \mathrm{~km}$ (with the number of semi-natural pastures within $1 \mathrm{~km}$ excluded), $A_{1}$ is the area of the semi-natural pastures within $1 \mathrm{~km}$ (with the size of the studied locality excluded), and $A_{10}$ is the area of semi-nat-

Table 1. Estimated variables of the studied localities.

\begin{tabular}{lll}
\hline Variable & Description & Type \\
\hline Locality size & Area $(\text { ha })^{1}$ & Continuous, log transf'd \\
Pasture density & The density of pastures in the surrounding area ${ }^{2}$ & Continuous \\
Grazing pressure & Low and medium $(0)$ or heavy grazing pressure $(1)^{3}$ & Categorical \\
Presence of trees & Open (0) or wooded $(1)$ semi-natural pasture & Categorical \\
Plant species & Number of indicator species present & Continuous \\
Butterfly species & Number of butterfly species found at each locality & Continuous \\
\hline
\end{tabular}

1 Follows the project "Ancient Meadows and Pastures", in some cases it is the total from several adjacent sub-localities.

2 Calculated as an index in equation (1) from the number and size of pastures situated within a radius of 1 and $10 \mathrm{~km}$ from the surveyed locality.

3 Heavy grazing pressure means that the sward height was less than $15 \mathrm{~cm}$ at the main part of the surveyed locality.

4 Among those used in the project "Ancient Meadows and Pastures". The species are regarded as indicators of grazed, unfertilized meadows and pastures (Lindahl 1997).

5 Observed concurrently with the survey of burnets. 
ural pastures within $10 \mathrm{~km}$ from the surveyed locality minus $A_{1}, \check{N}_{1}, \check{N}_{10}, \breve{A}_{1}, \breve{A}_{10}$ are the means of $N_{1}, N_{10}, A_{1}$ and $A_{10}$, respectively, for all 100 pastures of study. We used this index because these variables were strongly autocorrelated, so it would have been impossible to avoid confounding variables if these variables had been treated separately. The index reflects the possibility for species to persist (i.e. occur at the surveyed locality) and gets a high value if several small localities, instead of one large, occur in the surrounding. This is probably the case if increased asynchrony and heterogeneity decreases extinction risks (Sutcliffe et al. 1996, Kindvall 1996), and because habitat characteristics and management regimes are more variable between many small localities, compared to one large.

\subsection{Inventories}

The presence/absence of butterflies and burnets was recorded, at each of the 100 localities during one year between 1993 and 2001. The majority of the species occurring at a given site will be recorded if each locality is visited at least three times in appropriate weather conditions between June and August (Weibull et al. 2000, Nilsson 2002). We used a standard method for butterfly surveys (Pollard 1977), but with a lower number of visits per locality (3-6 times per year) and the extent of the survey limited to June-August. All surveys were carried out between 10 AM and 4 PM, at favourable weather conditions; if weather was capricious an extra visit was done, explaining the variation in the number of visits among localities. No surveys were carried out if temperature $<+17^{\circ} \mathrm{C}$, cloudiness $>50 \%$ or wind $>8 \mathrm{~m} / \mathrm{s}$. Between-year fluctuations probably have a minor influence on our results, as the analyses are based on presence/absence data that are more stable between years than abundance data (Pollard \& Yates 1993).

Each transect was designed to traverse a range of habitats considered to be representative of the locality. Within each habitat, places rich in flowers and with warm microclimate were intentionally sought out to increase the possibility of recording all present species. The length of a transect, and thus the time spent on each locality, increased with the size of the locality. On average, 40-80 minutes effective search time was spent on each locality. The majority of the specimens were easily identified in the field, but in exceptional cases individuals were caught for identification. For butterflies, total species richness was estimated, but also a subset of butterflies mainly occurring in pastures (Dal 1978, Henriksen \& Kreutzer 1982; Appendix 1) were constructed. Indicator plants were identified and surveyed in the Ancient Meadows and Pastures Survey (Måreby 1991).

\subsection{Statistics}

In multiple logistic regressions, the presence or absence of individual burnet species was used as dependent variable, and locality size, pasture density, grazing pressure and presence of trees as independent variables (Table 1). Insignificant variables $(p>0.1)$ were excluded from the final model using backward elimination (log LR-sig.). The influence of habitat variables on species richness of burnets (square-root transformed to correct for non-normality), butterflies and plants was analysed using multiple linear regression. Insignificant variable(s) $(p>0.05)$ was excluded from the final model using backward elimination. The number of burnet, butterfly and plant species were used as dependent variables, and locality size, pasture density, grazing pressure and presence of trees as independent ones. The possible correlation between species richness of burnets, and that of butterflies, pasture butterflies and plants, was examined using Pearson product-moment two-tailed correlation coefficient. All statistical analyses were carried out by use of SPSS 10.05 Advanced Statistics software.

\section{Results}

The number of burnet species recorded per locality ranged from zero to five (mean $=1.75$ ). Five species were found, all with a frequency of $33 \%$ $36 \%$ of the localities. A. statices and Z. osterodensis were absent from the northern part of the study area, while Z. lonicerae was rare there (Fig. 2). Z. filipendulae alone had almost the same fre- 

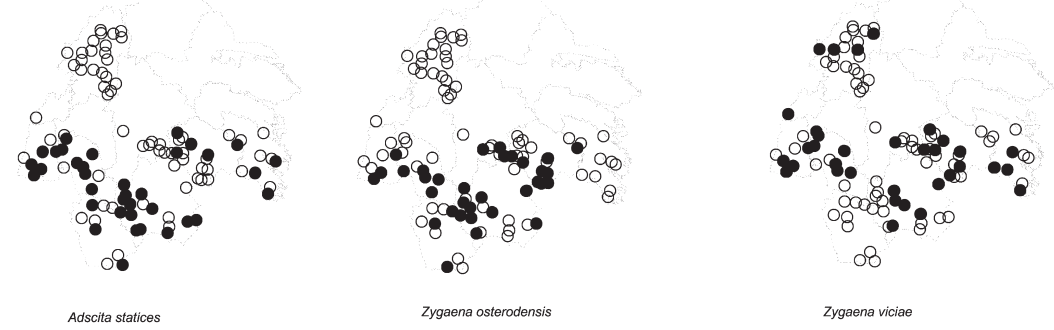

Fig. 2. Presence (filled) or absence (hollow circles) of burnet species (Zygaenidae) in the 100 surveyed seminatural pastures in the province of Östergötland, southeastern Sweden.
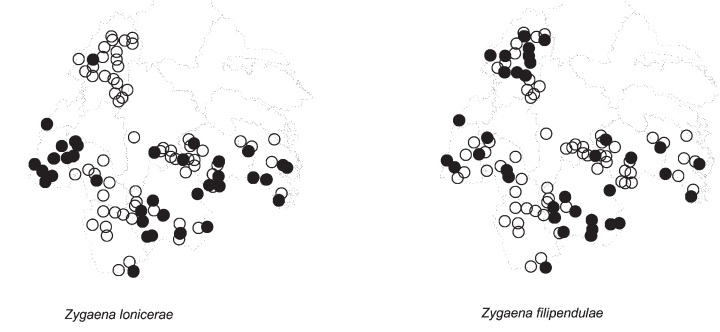

Table 2. Multiple logistic regression between the presence/absence of burnet species and characteristics of semi-natural pastures. For analysis details, see text, and for definitions of variables, see Table 1. Red-list category: LC = Least concern, NT = Near threatened, VU = Vulnerable (according to Gärdenfors 2000).

\begin{tabular}{|c|c|c|c|}
\hline Species/Variable & Source of variation & Slope & $p$ \\
\hline \multirow[t]{3}{*}{ Adscita statices Linnaeus, 1758 (NT) } & Pasture density & 0.33 & $<0.01$ \\
\hline & Presence of trees & -1.20 & 0.01 \\
\hline & Constant & 0.91 & \\
\hline \multirow{2}{*}{ Variables not in equation } & Locality size & $(+)$ & 0.22 \\
\hline & Grazing pressure & $(-)$ & 0.21 \\
\hline \multirow{3}{*}{ Zygaena osterodensis Reiss, 1921 (VU) } & Locality size & 1.18 & 0.05 \\
\hline & Grazing pressure & -1.02 & 0.06 \\
\hline & Constant & -1.42 & \\
\hline \multirow[t]{2}{*}{ Variables not in equation } & Pasture density & $(-)$ & 0.35 \\
\hline & Presence of trees & $(-)$ & 0.11 \\
\hline \multirow[t]{3}{*}{ Zygaena viciae Denis \& Schiffermüller 1775 (VU) } & Pasture density & 0.18 & 0.04 \\
\hline & Presence of trees & -1.05 & 0.02 \\
\hline & Constant & -0.62 & \\
\hline \multirow[t]{2}{*}{ Variables not in equation } & Locality size & $(+)$ & 0.34 \\
\hline & Grazing pressure & $(-)$ & 0.25 \\
\hline \multicolumn{4}{|l|}{ Zygaena filipendulae Linnaeus, 1758 (LC) } \\
\hline \multirow[t]{4}{*}{ Variables not in equation } & Locality size & $(+)$ & 0.14 \\
\hline & Pasture density & $(-)$ & 0.58 \\
\hline & Grazing pressure & $(-)$ & 0.08 \\
\hline & Presence of trees & $(-)$ & 0.34 \\
\hline \multirow[t]{4}{*}{ Zygaena lonicerae Scheven, 1777 (VU) } & Locality size & 1.87 & $<0.01$ \\
\hline & Grazing pressure & -1.28 & 0.02 \\
\hline & Presence of trees & -1.04 & 0.03 \\
\hline & Constant & -3.56 & \\
\hline Variables not in equation & Pasture density & $(+)$ & 0.29 \\
\hline
\end{tabular}


Table 3. Frequency of the presence of burnets in semi-natural pastures (see Table 1). Data in relative frequencies $(\%)$.

\begin{tabular}{|c|c|c|c|c|c|c|c|c|c|c|}
\hline \multirow[t]{2}{*}{ Species } & \multicolumn{3}{|c|}{ Locality size } & \multicolumn{3}{|c|}{ Pasture density } & \multicolumn{2}{|c|}{ Grazing pressure } & \multicolumn{2}{|c|}{ Presence of trees } \\
\hline & $0.6-4.0$ & $4.0-9.5$ & $9.5-48.8$ & $0.4-1.4$ & $1.4-2.9$ & $3-12$ & $\begin{array}{c}\text { low/ } \\
\text { medium }\end{array}$ & high & open & wooded \\
\hline$n$ & 33 & 33 & 34 & 33 & 33 & 34 & 70 & 30 & 41 & 59 \\
\hline Adscita statices & 18 & 36 & 53 & 15 & 45 & 47 & 39 & 30 & 49 & 27 \\
\hline Zygaena osterodensis & 21 & 33 & 44 & 27 & 36 & 35 & 39 & 20 & 44 & 25 \\
\hline Z. viciae & 18 & 33 & 50 & 33 & 27 & 41 & 37 & 27 & 46 & 25 \\
\hline Z. filipendulae & 24 & 45 & 38 & 39 & 42 & 26 & 41 & 23 & 41 & 32 \\
\hline Z. Ionicerae & 18 & 36 & 53 & 33 & 33 & 41 & 43 & 20 & 51 & 25 \\
\hline
\end{tabular}

quency of occurrence in all parts of the study area.

Two out of five species showed a positive correlation with the size of the locality, and three species had a higher frequency of occurrence in open pastures, compared to wooded ones (Tables 2-3). Z. lonicerae had a higher frequency of occupancy at low- and medium-grazed semi-natural pastures. The presence of $A$. statices and $Z$. viciae was positively related with pasture density (Table 2). The locality size and the pasture density correlated positively with each other (Table 1; Pearson $r=0.479, p<0.01)$. More burnets species were found on: (1) large semi-natural pastures, compared with small ones, 2) low- and medium- grazed semi-natural pastures, compared with heavily-grazed ones, and (3) open semi-natural pastures, compared with wooded ones (Table 4).

The number of burnet species per locality was positively correlated with the number of butterfly species and with the number of plant species (Table 5). Species richness among a subset of 24 butterfly species associated with pastures had even stronger correlation with the number of burnets than the total species richness of butterflies had (Table 5). Several localities harboured a relatively species rich butterfly fauna despite no burnets being present. If many burnets were observed present on a given locality, then also many

Table 4. Multiple linear regression for species richness of burnets, butterflies and plants in relation to locality size, pasture density, grazing pressure and presence of trees.

\begin{tabular}{llcr}
\hline Dependent variable & Source of variation & Slope & \multicolumn{1}{c}{$p$} \\
\hline Number of burnet species & Locality size & 0.71 & $<0.01$ \\
$n=100$ & Grazing pressure & -0.31 & 0.03 \\
& Presence of trees & -0.42 & $<0.01$ \\
Variables not in equation & Constant & -1.24 & 0.21 \\
Number of butterfly species & Locality size & $(+)$ & $<.45$ \\
$n=100$ & Grazing pressure & -4.28 & $<0.01$ \\
& Presence of trees & -3.05 & $<0.01$ \\
Variables not in equation & Constant & & 0.01 \\
Number of plant species & Pasture density & $(+)$ & 0.50 \\
$n=92$ & Locality size & 8.23 & $<0.01$ \\
Variables not in equation & Constant & 20.2 & 0.10 \\
& Presence of trees & $(-)$ & 0.94 \\
& Grazing pressure & $(-)$ & 0.98 \\
\hline
\end{tabular}



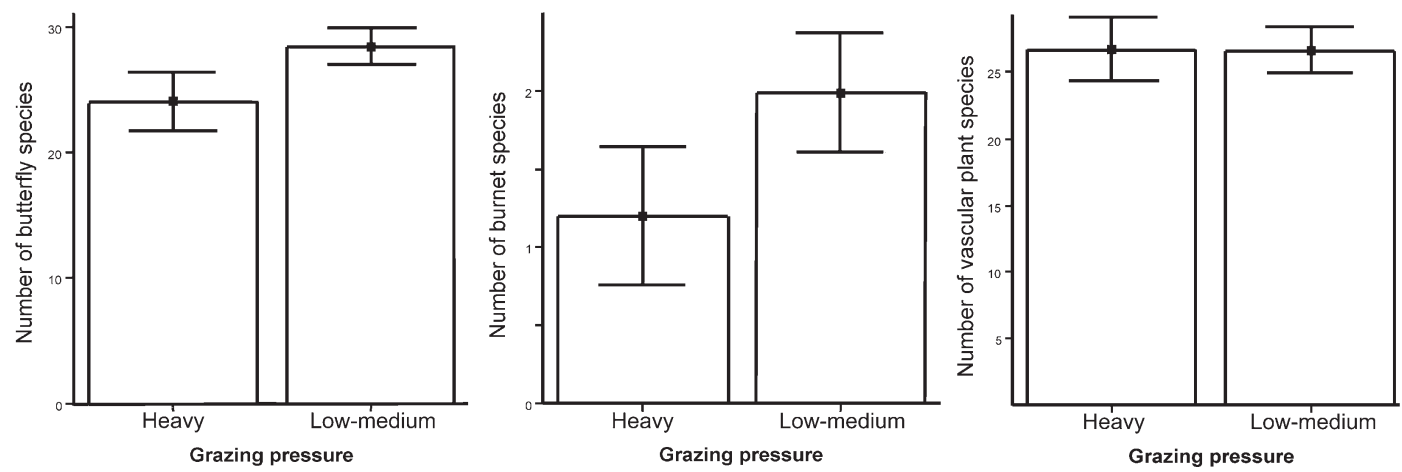

Fig. 3. The mean $( \pm 95 \% \mathrm{Cl})$ total number of butterfly, burnet and plant species (indicator species; Lindahl 1997) in relation to grazing pressure, estimated at 92 pastures in southeastern Sweden (see also Table 4).

butterfly species were present (Fig. 4).

Species richness of burnets and butterflies was higher in low- and medium-grazed localities, while a difference in grazing intensity did not affect species richness of plants (Table 4, Fig. 3). Species richness of the three focal groups responded to the amount of pastures in the surroundings, and locality size, in a similar way. All groups tended to be slightly more species rich at open localities compared with wooded ones, the trend being significant only for burnets and butterflies.

\section{Discussion}

\subsection{Burnet occurrence and species richness}

Larger localities hosted a more species-rich burnet fauna, compared to smaller ones. This can be
Table 5. Pearson correlation between the number of burnet species and butterfly species, pasture butterflies (Appendix 1) and indicator plant species recorded at each locality. The plant species consists of species considered as indicators of grazed, unfertilized meadows and pastures (see Table 1).

\begin{tabular}{llll}
\hline $\begin{array}{l}\text { Coefficient/ } \\
\text { Probability }\end{array}$ & Butterflies & $\begin{array}{l}\text { Pasture } \\
\text { butterflies }\end{array}$ & Plants \\
\hline$r$ & 0.60 & 0.87 & 0.22 \\
$p$ & $<0.001$ & $<0.001$ & 0.039 \\
\hline
\end{tabular}

explained by the fact that (1) larger patches of habitat are more often colonised and there is an increased risk for extinction in the small ones (e.g. Thomas \& Harrison 1992), (2) larger patches can potentially contain more types of habitat, which in turn increases environmental heterogeneity (Pollard \& Yates 1993), and (3) the
Fig. 4. - a. The number of butterfly species $\left(R^{2}=0.34\right)$ in relation to the number of burnet species in 100 semi-natural pastures. $-b$. The number of plants $\left(R^{2}\right.$ $=0.05$ ) in relation to the number of burnet species in 92 seminatural pastures.
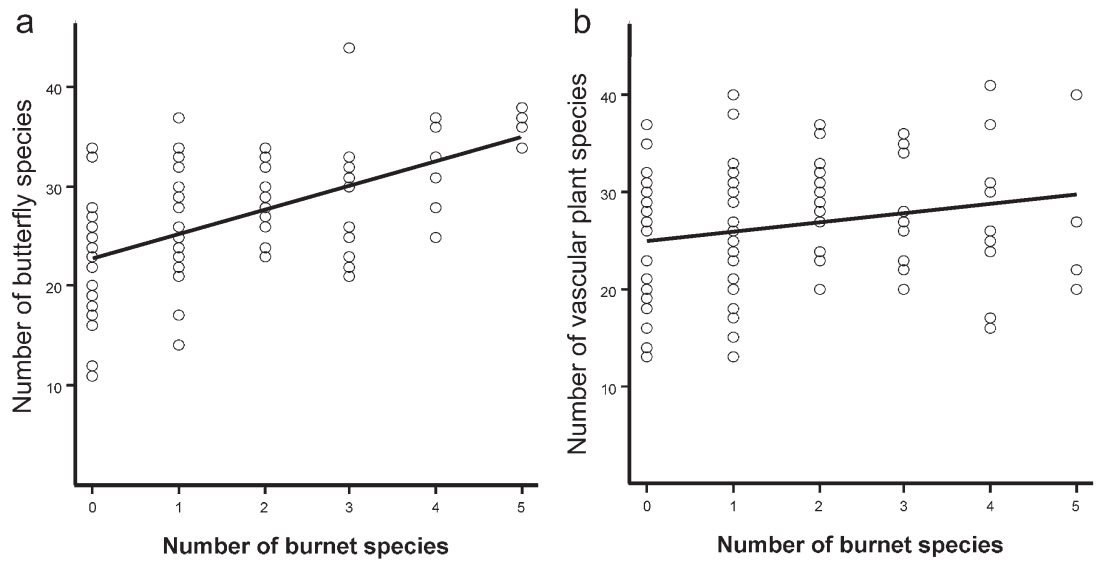
probability of recording a species is higher along a longer transect, compared with a shorter one (Pollard \& Yates 1993, Hellmann \& Fowler 1999).

A. statices and $Z$. viciae occurred in a higher frequency at localities surrounded by a high density of pastures. This may be an effect of higher colonisation rates and/or lower extinction risk due to the rescue effect (Brown \& Kodric-Brown 1977) in landscapes with a high density of suitable patches of habitat. This may result from a metapopulation structure; the density of suitable patches may be too low to permit metapopulation survival in those parts of the study area where the species were absent, while the frequency of presence may be relatively high in landscapes where the habitat density still exceeds a threshold, enabling metapopulations to sustain. The spatial distribution of many butterfly species is limited due to the landscape composition and the shortage of suitable habitat patches (Warren et al. 2001, Asher et al. 2001). Modelling has been a useful tool for understanding the present occurrence pattern and predicting extinction risks for butterfly species (León-Cortés et al. 2003a, b), and might also be useful for the studied burnet species. However, to get a reliable outcome from such models, studies on the population ecology of these species, especially their dispersal, are necessary. Mark-recapture studies have shown that burnets are sedentary, but they may be able to disperse long distances; the longest flight distance recorded for burnets is $3.3 \mathrm{~km}$ (Kreusel 1999). Movements of over three kilometres are usually not observed among sedentary butterflies (Schneider 2003).

Species richness of burnets was lower in wooded pastures, compared with open ones, possibly because the shading from the trees generates an unfavourable microclimate for the burnet larvae. Another possible explanation is that the habitat quality may be lower because the amount of plants, used for adult feeding and larval food, is lower (Greatorex-Davies et al. 1993, Pollard \& Yates 1993).

At localities with a heavy grazing pressure, the species richness of burnets was lower; heavy grazing has been shown to be detrimental for burnets (Naumann et al. 1999, Waring 2001). However, Ravenscroft and Young (1996) studied $Z$. loti in Scotland and found that the species occurred only in areas with short vegetation and warm microclimate, often as a consequence of heavy grazing. One reason why heavy grazing is detrimental for burnets may be that the larvae and puparia of burnets occur exposed on stalks (Tremewan 1985, Schmidt-Loske 1993, Bourn 1995) and consequently become susceptible to grazing or mowing. Also butterflies may be sensitive to heavy grazing (Fig. 3, Warren 1993, Thomas 1995, Balmer \& Erhardt 2000, Franzén \& Ranius 2004).

\subsection{Correlation between burnet species and other taxa}

The number of burnet species per locality correlated positively with the number of butterfly species, especially with those considered to be associated with pastures (Table 5), possibly reflecting the fact that burnets and butterflies in general have similar biology and habitat requirements. However, the correlation between the number of burnet species and that of plant species was surprisingly weak, possibly resulting from different responses to grazing pressure among species richnesses of burnets, butterflies and vascular plants (Fig. 3). The correlation between species richness of butterflies and burnets is at least partly due to the similar preference for low grazing-intensity localities, while the correlation with species richness of plants is weaker because the plant species richness may be independent of grazing pressure (Fig 3). Erhardt and Thomas (1991) found that there is often an association between plants and number of butterfly species, but that their responses to management differ. The majority of the plants occurring at grassland habitats are susceptible to heavy grazing mainly because their roots seldom experience any damage, and disturbance caused by grazing favours seed production and increases growth (Ekstam \& Forshed 1992). For that reason, it is important to avoid uniformly managed pastures with heavy grazing. To preserve burnets and other insects, the grazing pressure should be lower at least on some areas within the localities.

In Sweden, mainly vascular plants have been taken in consideration in the conservation of pas- 
tures and meadows (Ekstam \& Forshed 1992). Despite being the most species-rich taxon, insects have rarely been given priority in conservation measures of pastures, although insects are potentially useful biodiversity indicators, as their richness correlates with total biodiversity (e.g. Lambeck 1997, McGeoch 1998, Kerr et al. 2000). The lack of correlation between different insect taxa makes it impossible to identify one single group that can be used as indicators for all taxa (Faith \& Walker 1996, Dufrêne \& Legendre 1997, Duelli \& Obrist 1998, Vessby et al. 2002). The strong correlation between species richness of burnets and butterflies makes burnets promising as indicators of species-rich semi-natural pastures, but they should be used together with other groups, such as vascular plants. The use of burnets as indicators is supported by a study in southern Germany, where Kreusel (1999) demonstrated that pastures with any burnets sustained $90 \%$ of the endangered butterfly species in the area. Burnets are still relatively frequent in our study area, are easy to survey as they have conspicuous aposematic wing patterns, are mainly sedentary, are low-flying, and may be abundant (Naumann et al. 1999). Another advantage with using burnets as indicators is that they frequently visit flowers and are often relatively long living (Naumann et al. 1999).

The main problem with the use of burnets as biodiversity indicators is that their ecology is poorly known. Consequently, we do not know e.g. the spatial and temporal scales where burnets respond to habitat changes. Further studies in accordance with those of many butterflies (e.g. Thomas et al. 1992, Hanski \& Thomas 1994, Thomas 2000) should be carried out to achieve detailed knowledge about burnet population structure and habitat requirements.

Acknowledgements. Kjell Antonsson initiated the survey and made all necessary data available. Svante Gynnemo carried out part of the field work. Lars-Owe Wikars and Mats Jonsell provided valuable comments on the manuscript.

\section{References}

Anonymous 1990: Betesmarker - historiska data. Statistiska meddelanden Na 36 SM 9001. — Natur- vårdsverket, Stockholm. [In Swedish.]

Anonymous 1996: Sveriges geografi. Sveriges Nationalatlas. — Lantmäteriet, Gävle. [In Swedish.]

Asher, J., Warren, M. S., Fox, R., Harding, P., Jeffcoate, G. \& Jeffcoate, S. 2001: The millennium atlas of butterflies in Britain and Ireland. - Oxford University Press, Oxford. 433 pp.

Balmer, O. \& Erhardt, A. 2000: Consequences of succession on extensively grazed grasslands for central European butterfly communities: rethinking conservation practices. - Conservation Biology 14: 746-757.

Barbour, D. A. \& Waring, P. 1991: The new forest burnet moth Zygaena viciae (Denis and Schiffermueller) (Lepidoptera: Zygaenidae) in Scotland in 1990. — Entomologist's Gazette 42: 231-238.

Bourn, N. A. D. 1995: The ecology, conservation and population genetics of three species of Zygaenid moths, Zygaena lonicerae, Zygaena purpuralis and Zygaena filipendulae in North west Scotland. - PhD thesis, University of Aberdeen. 267 pp.

Brown, J. H. \& Kodric-Brown, A. 1977: Turnover rates in insular biogeography: effect of immigration on extinction. - Ecology 58: 445-449.

Cowley, M. J. R., Thomas, C. D., Wilson, R. J., LeónCortés, J. L., Gutiérrez, D. \& Bulman, C. R. 2001: Density-distribution relationships in British butterflies. II. An assessment of mechanisms. - J. Anim. Ecol. 70: 426-441.

Crispin, M. J. \& Warrington, S. 1997: Aspects of the population ecology of Zygaena filipendulae (Linnaeus) (Lepidoptera: Zygaenidae). — Entomologist's Gazette 48: 97-105.

Dal, B. 1978: Fjärilar i naturen. Europas dagfjärilar. Nordeuropa. - Wahlström \& Widstrand, Stockholm. 123 pp. [In Swedish.]

Duelli, P. \& Obrist, M. K. 1998: In search of the best correlates for local organismal biodiversity in cultivated areas. - Biodiv. Conserv. 7: 297-309.

Dufrêne, M. \& Legendre, P. 1997: Species assemblages and indicator species: The need for a flexible asymmetrical approach. - Ecol. Monogr. 67: 345-366.

Ekstam, U. \& Forshed, N. 1992: Om hävden upphör. Kärlväxter som indikatorer i ängs- och hagmarker. Naturvårdsverket, Stockholm. 135 pp. [In Swedish.]

Erhardt, A. \& Thomas, J. A. 1991: Lepidoptera as indicators of change in the semi-natural grasslands of lowland and upland europe. - In: Collins, N. M. \& Thomas, J. A. (eds.), The conservation of insects and their habitats: 213-236. Academic Press, London.

Faith, D. P. \& Walker, P. A. 1996: Environmental diversity: On the best-possible use of surrogate data for assessing the relative biodiversity of sets of areas. Biodiversity and Conservation 5: 399-415.

Franzén, M. \& Ranius, T. 2004: Occurrence patterns of butterflies (Rhopalocera) in semi-natural pastures in southeastern Sweden. - Journal for Nature Conservation (in press).

Gärdenfors, U. 2000: The 2000 redlist of Swedish species. - Swedish Species Information Centre, Uppsala.

Greatorex-Davies, J. N., Sparks, T. H., Hall, M. L. \& 
Marrs, R. H. 1993: The Influence of shade on butterflies in rides of coniferized lowland woods in southern England and implications for conservation management. - Biological Conservation 63: 31-41.

Gutiérrez, D., León-Cortés, J. L., Menéndez, R., Wilson, R. J., Cowley, M. J. R. \& Thomas, C. D. 2001: Metapopulations of four lepidopteran herbivores on a single host plant, Lotus corniculatus. - Ecology 82: 13711386.

Hansen, L. O. \& Aarvik, L. 2000: Sjeldne insekter i Norge 3. Sommerfugler (Lepidoptera). Fagrapport 38. NINA, Trondheim. 145 pp. [In Norwegian.]

Hanski, I. \& Thomas, C. D. 1994: Metapopulation dynamics and conservation - a spatially explicit model applied to butterflies. - Biological Conservation 68: 167-180.

Hellmann, J. J. \& Fowler, G. W. 1999: Bias, precision, and accuracy of four measures of species richness. - Ecological Applications 9: 824-834.

Henriksen, H. J. \& Kreutzer, I. B. 1982: The butterflies of Scandinavia in nature. - Skandinavisk Bogforlag, Odense. 215 pp.

Huldén, L., Albrecht, A., Itämies, J., Malinen, P. \& Wettenhovi, J. 2000: Atlas of Finnish Macrolepidoptera. Lepidopterologiska sällskapet i Finland, Helsingfors.

Karsholt, O. \& Razowski, J. 1996: The Lepidoptera of Europe. A distributional checklist. - Apollo books, Stenstrup.

Kerr, J. T., Sugar, A. \& Packer, L. 2000: Indicator taxa, rapid biodiversity assessment, and nestedness in an endangered ecosystem. - Conservation Biology 14: 1726-1734.

Kindvall, O. 1996: Habitat heterogeneity and survival in a bush cricket metapopulation. - Ecology 77: 207214.

Kreusel, B. 1999: Dispersionsdynamik von Widderchen zwischen verinselten Kalkmagerrasen in Sueddeutschland unter besonderer Beruecksichtigung von Naturschutzaspekten. - Natur und Landschaft 74: 255-265. [In German.]

Kruess, A. \& Tscharntke, T. 2002: Contrasting responses of plant and insect diversity to variation in grazing intensity. - Biological Conservation 106: 293-302.

Kulfan, M. \& Kulfan, M. 1996: Distribution and conservation of burnets (Lepidoptera, Zygaenidae) in Slovakia. — Folia Faunistica Slovaca 14: 59-68.

Lambeck, R. J. 1997: Focal species: A multi-species umbrella for nature conservation. - Conservation Bio$\operatorname{logy} 11: 849-856$.

León-Cortés, J. L., Lennon, J. J. \& Thomas, C. D. 2003a: Ecological dynamics of extinct species in empty habitat networks. 1. The role of habitat pattern and quantity, stochasticity and dispersal. - Oikos 102: 449464.

León-Cortés, J. L., Lennon, J. J. \& Thomas, C. D. 2003b: Ecological dynamics of extinct species in empty habitat networks. 2. The role of host plant dynamics. Oikos 102: 465-477.

Lind, H. \& Lindeborg, M. 1989: Fjärilar som presumtiva pollinatörer av salepsrot, Anacamptis pyramidalis. -
Entomologisk Tidskrift 110: 156-160. [In Swedish.] Lindahl, C. 1997: Ängs- och hagmarker i Sverige. Rapport 4819. - Naturvårdsverket, Stockholm. 144 pp. [In Swedish.]

Måreby, S. 1991: Ängs- och hagmarker i Östergötland. Länsstyrelsen i Östergötlands län, Linköping. 55 pp. [In Swedish.]

McGeoch, M. A. 1998: The selection, testing and application of terrestrial insects as bioindicators. - Biological Reviews 73: 181-201.

Menéndez, R., Gutiérrez, D. \& Thomas, C. D. 2002: Migration and Allee effects in the six-spot burnet moth Zygaena filipendulae. - Ecological Entomology 27: 317-325.

Mikkola, K. 1979: Vanishing and declining species of Finnish Lepidoptera. — Notulae Entomologiae 59: 19.

Mikkola, K. 1987: Changes in the Finnish Lepidopteran fauna since 1950 in relation to environmental changes. — Entomologiska Meddelser. 55: 107-114.

Naumann, C. M., Tarmann, G. M. \& Tremewan, W. G. 1999: Western Palaearctic Zygaenidae. - Apollo Books, Stenstrup.

Nazarov, V. V. 1993: On the role of Zygaenidae (Lepidoptera) in pollination of Anacamptis pyramidalis (Orchidaceae). - Zool. Zh. 72: 54-67. [In Russian.]

Nilsson, S. G. 2002: En metod for kvantitativa inventeringar av dagfjärilar och bastardsvärmare på landskapsnivå. - Entomologisk Tidskrift 123: 193201. [In Swedish.]

Oliver, I. \& Beattie, A. J. 1996: Invertebrate morphospecies as surrogates for species: A case study. - Conservation Biology 10: 99-109.

Pärt, T. \& Söderström, B. 1999: Conservation value of semi-natural pastures in Sweden: Contrasting botanical and avian measures. - Conservation Biology 13: 755-765.

Pollard, E. 1977: A method for assesing changes in the abundance of butterflies. - Biological Conservation 12: $115-134$.

Pollard, E. \& Yates, T. J. 1993: Monitoring butterflies for ecology and conservation. - Chapman and Hall, London. 274 pp.

Pullin, A. S. 1995: Ecology and conservation of butterflies. - Chapman and Hall, London. 363 pp.

Ravenscroft, N. O. M., Bourn, N. A. D. \& Young, M. R. 1993: Initial responses of the New Forest Burnet moth, Zygaena viciae (Denis and Schiffermueller) (Lepidoptera: Zygaenidae), to recovery attempts in Scotland. — Entomologist's Gazette 44: 104.

Ravenscroft, N. O. M. \& Young, M. R. 1996: Habitat specificity, restricted range and metapopulation persistence of the slender scotch burnet moth Zygaena loti in western Scotland. - J. Applied Ecology 33: 993 1000.

Saarinen, K., Lahti, T. \& Marttila, O. 2003: Population trends of Finnish butterflies (Lepidoptera : Hesperioidea, Papilionoidea) in 1991-2000. — Biodiversity and Conservation 12: 2147-2159.

Schmidt-Loske, K. 1993: Spatial distribution of and habi- 
tat use by Zygaena filipendulae (Linnaeus, 1758) (Lepidoptera, Zygaenidae) in a suburban nature reserve. - In: Tremewan, W. G., Wipking, W. \& Naumann, C. M. (eds.), Proceedings of the 5th international symposium on the biology of the Zygaenidae (Insecta, Lepidoptera): 165-175. Koeltz scientific books, Königstein. 283 pp.

Schneider, C. 2003: The influence of spatial scale on quantifying insect dispersal: an analysis of butterfly data. - Ecological Entomology 28: 252-256.

Sutcliffe, O. L., Thomas, C. D. \& Moss, D. 1996: Spatial synchrony and asynchrony in butterfly population dynamics. - Journal of Animal Ecology 65: 85-95.

Thomas, C. D. 1994: Extinction, colonization, and metapopulations - environmental tracking by rare species. - Conservation Biology 8: 373-378.

Thomas, C. D. 2000: Dispersal and extinction in fragmented landscapes. - Proceedings of the Royal Society of London ser. B Bio. 267: 139-145.

Thomas, C. D. \& Harrison, S. 1992: Spatial dynamics of a patchily distributed butterfly species. - Journal of Animal Ecology 61: 437-446.

Thomas, C. D., Thomas, J. A. \& Warren, M. S. 1992: Distributions of occupied and vacant butterfly habitats in fragmented landscapes. — Oecologia 92: 563-567.

Thomas, J. A. 1984: The conservation of butterflies in temperate countries: past efforts and lessons for the future. - In: Vane-Wright, R. I. \& Ackery, P. R. (eds.), The biology of butterflies: 333-353. Academic press, London. 429 pp.

Thomas, J. A. 1995: The conservation of declining butterfly populations in Britain and Europe: Priorities, problems and successes. - Biological Journal of Linnean Society 56: 55-72.

Tremewan, W. G. 1985: Zygaenidae. — In: Heath, J. \& Emmet, A. M. (eds.), The moths and butterflies of Great Britain and Ireland 2: 74-123. Colchester. 411 pp.
Väisänen, R. \& Somerma, P. 1993: Suomen punatäpläperhoset (Zygaenidae of Finland). — Baptria 18: 149. [In Finnish.]

van Swaay, C. A. M. \& Warren, M. S. 2003: Red data book of European butterflies (Rhopalocera). Nature and environment, No 99. - Council of Europe, Strasbourg. 260 pp.

Vessby, K., Söderström, B., Glimskär, A. \& Svensson, B. 2002: Species-richness correlations of six different taxa in Swedish seminatural grasslands. - Conservation Biology 16: 430-439.

Waring, P. 2001: Grazing and cutting as conservation management tools: The need for a cautious approach, with some examples of rare moths which have been adversely affected. - Entomologists Record and Journal of Variation 113: 193-200.

Warren, M. S. 1993: A review of butterfly conservation in central southern Britain. II. Site management and habitat selection by key species. - Biological Conservation 64: 37-49.

Warren, M. S., Hill, J. K., Thomas, J. A., Asher, J., Fox, R., Huntley, B., Roy, D. B., Telfer, M. G., Jeffcoate, S., Harding, P., Jeffcoate, G., Willis, S. G., GreatorexDavies, J. N., Moss, D. \& Thomas, C. D. 2001: Rapid responses of British butterflies to opposing forces of climate and habitat change. - Nature 414: 65-69.

Watkinson, A. R. \& Ormerod, S. J. 2001: Grasslands, grazing and biodiversity: editors' introduction. - Journal of Applied Ecology 38: 233-237.

Weibull, A. C., Bengtsson, J. \& Nohlgren, E. 2000: Diversity of butterflies in the agricultural landscape: the role of farming system and landscape heterogeneity. Ecography 23: 743-750.

Zarzycki, K. \& Dabrowski, J. S. 1986: Food plants of burnets (Zygaena F., Lepidopt., Zygaenidae) and the dying-out of these moths in the Pienny Mts. (Poland). Acta. Soc. Bot. Pol. 55: 343-360.

Appendix 1. Butterfly species associated with semi-natural grassland in systematic order. Nomenclature follows Karsholt \& Razowski (1996).

\begin{tabular}{|c|c|c|}
\hline Pyrgus malvae & Plebejus idas & Clossiana euphrosyne \\
\hline Thymelicus lineola & Aricia artaxerxes & Clossiana selene \\
\hline Hesperia comma $^{1}$ & Cyaniris semiargus & Melitaea cinxia \\
\hline Ochlodes faunus & Polyommatus amandus & Mellicta britomartis ${ }^{1}$ \\
\hline Lycaena phlaeas & Polyommatus icarus & Mellicta athalia \\
\hline Lycaena virgaureae & Mesoacidalia aglaja & Coenonympha arcania \\
\hline Lycaena hippothoe & Fabriciana adippe & Coenonympha pamphilus \\
\hline Cupido minimus $^{1}$ & Fabriciana niobe $^{1}$ & Maniola jurtina \\
\hline
\end{tabular}

1 Red-listed species (Gärdenfors 2000) 